\title{
IMPLEMENTASI SUPPORT VECTOR MACHINE UNTUK ANALISIS SENTIMEN PENGGUNA TWITTER TERHADAP PELAYANAN TELKOM DAN BIZNET
}

\author{
Fadholi Fat Haranto1; Bety Wulan Sari ${ }^{2}$ \\ ${ }^{1}$ Informatika, ${ }^{2}$ Sistem Informasi \\ Universitas AMIKOM Yogyakarta \\ www.amikom.ac.id \\ ${ }^{1}$ fadholi.haranto@students.amikom.ac.id, ${ }^{2}$ bety@amikom.ac.id \\ *Correspondent Author
}

\begin{abstract}
Social media is a media that can be used for expression by its users. Twitter is quite popular and is often used in Indonesia, Twitter users can express and aspire without restrictions. Tweets in the form of expressions and aspirations written by Twitter users can be used to review a product or service. In this study, researchers used text mining techniques by applying the Support Vector Machine algorithm which is used for twitter user sentiment analysis of Telkom and Biznet services. Data on Telkom and Biznet services will be calculated in this study with a number of datasets of 500 tweets originating from twitter crawling data, there are 250 tweets that are used as datasets for each object. Some of the data will be used for training data and testing data in the modeling process using the Support Vector Machine algorithm. The method used for testing the model is Confusion Matrix while $K$ Fold Cross Validation is intended to divide the training data and testing data according to the folds used. The test results obtained using the K-Fold Cross Validation and Confusion Matrix methods on the model are made using the Support Vector Machine algorithm which results in $79.6 \%$ accuracy, $76.5 \%$ precision, $72.8 \%$ recall, and F1-score accuracy 74 , $6 \%$ for Telkom, and accuracy of $83.2 \%$, precision $78.8 \%$, recall $71.6 \%$, and 11 -score $75 \%$ for Biznet.
\end{abstract}

Keywords: Sentiment Analysis, Support Vector Machine, Classification, Biznet, Telkom.

Intisari- Sosial media merupakan suatu media yang dapat digunakan untuk berekspresi oleh penggunanya. Twitter cukup populer dan sering digunakan di Indonesia, pengguna twitter dapat berekspresi dan beraspirasi tanpa adanya batasan. Tweet yang berupa ekspresi dan aspirasi yang ditulis oleh pengguna twitter dapat digunakan untuk ulasan sebuah produk atau layanan. Pada penelitian ini, peneliti menggunakan teknik text mining dengan menerapkan algoritma Support Vector Machine yang dipergunakan untuk analisis sentimen pengguna twitter terhadap pelayanan
Telkom dan Biznet. Data pada pelayanan Telkom dan Biznet akan dilakukan perhitungan pada penelitian ini dengan jumlah dataset sebanyak 500 tweet yang berasal dari crawling data twitter, terdapat 250 tweet yang dijadikan dataset pada masing-masing objek. Sejumlah data tersebut akan dipergunakan untuk data training serta data testing dalam proses pembuatan model menggunakan algoritma Support Vector Machine. Metode yang digunakan untuk pengujian model adalah Confusion Matrix sedangkan K-Fold Cross Validation ditujukan untuk untuk membagi data training dan data testing sesuai lipatan yang digunakan. Hasil pengujian yang diperoleh menggunakan metode $K$-Fold Cross Validation dan Confusion Matrix pada model yang dibuat menggunakan algoritma Support Vector Machine yang memberikan hasil nilai accuracy $79,6 \%$, precision $76,5 \%$, recall $72,8 \%$, dan $F 1$-score $74,6 \%$ untuk Telkom, serta accuracy 83,2\%, precision $78,8 \%$, recall $71,6 \%$, dan $F 1$-score $75 \%$ untuk Biznet.

Kata Kunci: Analisis Sentimen, Support Vector Machine, Klasifikasi, Biznet, Telkom.

\section{PENDAHULUAN}

Jumlah pengguna internet di Indonesia bertumbuh dengan pesat sebesar $10,12 \%$ dari tahun 2017 saat angka penetrasi sebanyak 54,46\%. Hasil tersebut diperoleh dari Polling Indonesia dengan Asosiasi Penyelenggara Jasa Internet Indonesia. (Pratomo, 2019)

Saat ini media sosial seperti Facebook, Twitter, LinkedIn, YouTube menjadi bagian dari kehidupan manusia termasuk dalam hal berinteraksi dengan lainnya. Selain digunakan untuk interaksi sosial, media ini juga sebagai identitas diri ke masyarakat umum. (Susilo \& Rochimah, 2013) 
Dalam media sosial, setiap status yang diunggah oleh pengguna, tidak semuanya bermakna akademis. Sehingga dibutuhkan klasifikasi dokumen untuk dapat mengetahui perbedaan status bertopik akademis dari yang non-akademis. Status-status ini juga mempunyai sentimen dari penulisnya. Dengan melakukan analisis sentimen, dapat diketahui informasi tentang emosi pengguna (Susilo \& Rochimah, 2013)

Opinion mining atau analisis sentiment merupakan bagian dari text mining yang melakukan studi mengenai opini orang-orang, sentimen, evaluasi, tingkah laku dan emosi terhadap suatu entitas seperti produk, layanan, organisasi, individu, permasalahan, topik, acara dan atribut-atributnya (Liu, 2012)

Hal ini membuat produk-produk besar maupun kecil, luar negeri maupun dalam negeri kemudian berlomba-lomba melakukan pemasaran via Twitter ke pasar Indonesia. Mereka membuat akun twitter dan kemudian menunggu reply atau mention dari pengguna lain untuk mengetahui bagaimana respon atas produk mereka (Monarizqa, Nugroho, \& Hantono, 2014)

Hal yang paling penting untuk melakukan analisis komentar yang terdapat di Twitter adalah dengan melakukan analisis sentimen. Setelah dilakukan analisis sentimen, lalu diterjemahkan sehingga menjadi sesuatu yang lebih berarti yaitu salah satunya dalam bentuk rating. Rating ini menjadi penting bagi ranah bisnis karena bisa dijadikan salah satu parameter kesuksesan. (Monarizqa et al., 2014).

Banyak algoritma yang digunakan ntuk melakukan analisis sentimen, disini peneliti akan menerapkan algoritma Support Vector Machine (SVM).

SVM merupakan salah satu metode klasifikasi dengan menggunakan metode machine learning (supervised learning) yang memprediksi kelas berdasarkan pola dari hasil proses training yang diciptakan oleh Vladimir Vapnik. Klasifikasi dilakukan dengan garis pembatas (hyperlane) yang memisahkan antara kelas opini positif dan opini negatif. Secara intuitif, suatu garis pembatas yang baik adalah yang memiliki jarak terbesar ke titik data pelatihan terdekat dari setiap kelas, karena pada umumnya semakin besar margin, semakin rendah error generalisasi dari pemilah. Margin adalah jarak dari suatu titik vektor di suatu kelas terhadap hyperplane (Santoso, Virginia, \& Lukito, 2017)

Penelitian lainnya dilakukan oleh (Preety \& Dahiya, 2015) yang berjudul Sentimen Analysis Using SVM and Nä̈ve Bayes Algrorithm. Penelitian ini membandingkan metode Support Vector Machine dengan metode Nä̈ve Bayes dimana metode Support Vector Machine memiliki hasil akhir klasifikasi lebih tinggi daripada metode Naïve Bayes yaitu 83.59\% banding 79.66\%.

Oleh karena itu peneliti bermaksud membuat sebuah aplikasi analisis sentimen pengguna twitter terhadap pelayanan Telkom dan Biznet menggunakan algoritma Support Vector Machine yang digunakan oleh Telkom dan Biznet, dengan tujuan mengetahui presentase sentimen negatif dan positif dari Telkom dan Biznet sehingga kedua perusahaan tersebut bisa meningkatkan pelayanan yang lebih baik.

\section{BAHAN DAN METODE}

Penelitian ini melakukan beberapa tahapan dengan metode sebagai berikut :

1. Pengumpulan data

Data tweet diambil dari twitter, pengambilan data dilakukan dengan cara crawling data yang ada di twitter yang berhubungan dengan Telkom dan Biznet. Data yang diambil adalah 500 data, pada masing-masing objek memiliki 250 tweet yang digunakan sebagai data training. 250 data Telkom sebanyak 103 tweet positif serta 147 tweet negatif, sedangkan Biznet terdapat 88 tweet positif serta 162 tweet negatif.

\section{Preprocessing}

Preprocessing menjadi proses awal sebelum melakukan klasifikasi. Proses ini digunakan untuk membersihkan data dari noise dan siap untuk digunakan pada proses selanjutnya, berikut merupakan tahap-tahap preprocessing:

a. Cleaning

Pada proses cleaning kalimat dibersihkan dari hashtag, mention, dan juga tanda baca.

b. Case Folding

Merupakan proses penggantian huruf dari huruf yang bercampur (lowercase dan uppercase) menjadi semua huruf kecil.

c. Tokenization

Tokenization ialah proses perubahan kalimat menjadi kata.

d. Stopword

Merupakan penghilangan kata yang sering berbobot namun sering muncul.

3. Transformation

Term Frequency-Inverse Document Frequency (TF-IDF) digunakan pada proses transformation dengan cara merubah kalimat atau kata menjadi angka agar bisa diklasifikasi dan menggunakan Cosine Similarity untuk melihat kemiripan antar kata atau dokumen.

4. Klasifikasi

Untuk klasifikasi text menggunakan algoritma Support Vector Machine yang ditujukan untuk membuat model klasifikasi.

5. Evaluasi dan Hasil Validasi 
Metode untuk mengevaluasi algoritma yang digunakan yaitu dengan $k$-fold (10-fold) cross validation serta confusion matrix yang menghasilkan accuracy, precision, recall, f1-score.

\section{HASIL DAN PEMBAHASAN}

Penerapan algoritma Support Vector Machine terhadap hasil dari analisis sentiment menghasilkan penjelasan di bawah ini.

Untuk mengevaluasi program peneliti menggunakan metode 10-Fold Cross Validation, dan Confussion matrix. Confussion Matrix digunakan untuk mencari nilai accuracy, precision, recall, dan F1-score, sedangkan 10-Fold Cross Validation digunakan untuk membagi dataset ke dalam data training dan data testing. Evaluasi ini ditujukan untuk menentukan presentase keakuratan dari suatu model yang dibuat. Dalam pengujian ini akan dilakukan prediksi terhadap data testing menggunakan data training hasil dari Cross Validation. Berikut merupakan tabel yang menunjukkan performa dari tiap-tiap fold yang diuji.

Tabel 1. Hasil 10 Fold Cross Validation Telkom

\begin{tabular}{|c|c|c|}
\hline Fold & Parameter & Hasil(\%) \\
\hline \multirow{5}{*}{ Fold 1} & Accuracy & 76 \\
\hline & Precision & 80 \\
\hline & Recall & 44 \\
\hline & F1-score & 57 \\
\hline & Jumlah Data & 25 \\
\hline \multirow{5}{*}{ Fold 2} & Accuracy & 76 \\
\hline & Precision & 67 \\
\hline & Recall & 67 \\
\hline & F1-score & 67 \\
\hline & Jumlah Data & 25 \\
\hline \multirow{5}{*}{ Fold 3} & Accuracy & 72 \\
\hline & Precision & 86 \\
\hline & Recall & 50 \\
\hline & F1-score & 63 \\
\hline & Jumlah Data & 25 \\
\hline \multirow{5}{*}{ Fold 4} & Accuracy & 84 \\
\hline & Precision & 83 \\
\hline & Recall & 83 \\
\hline & F1-score & 83 \\
\hline & Jumlah Data & 25 \\
\hline \multirow{5}{*}{ Fold 5} & Accuracy & 84 \\
\hline & Precision & 83 \\
\hline & Recall & 83 \\
\hline & F1-score & 83 \\
\hline & Jumlah Data & 25 \\
\hline \multirow{5}{*}{ Fold 6} & Accuracy & 80 \\
\hline & Precision & 71 \\
\hline & Recall & 63 \\
\hline & F1-score & 67 \\
\hline & Jumlah Data & 25 \\
\hline \multirow{3}{*}{ Fold 7} & Accuracy & 80 \\
\hline & Precision & 67 \\
\hline & Recall & 89 \\
\hline
\end{tabular}

\begin{tabular}{|c|c|c|}
\hline Fold & Parameter & Hasil(\%) \\
\hline & F1-score & 76 \\
\hline & Jumlah Data & 25 \\
\hline \multirow{5}{*}{ Fold 8} & Accuracy & 84 \\
\hline & Precision & 89 \\
\hline & Recall & 73 \\
\hline & F1-score & 80 \\
\hline & Jumlah Data & 25 \\
\hline \multirow{5}{*}{ Fold 9} & Accuracy & 84 \\
\hline & Precision & 73 \\
\hline & Recall & 100 \\
\hline & F1-score & 85 \\
\hline & Jumlah Data & 25 \\
\hline \multirow{5}{*}{ Fold 10} & Accuracy & 76 \\
\hline & Precision & 70 \\
\hline & Recall & 70 \\
\hline & F1-score & 70 \\
\hline & Jumlah Data & 25 \\
\hline \multirow{5}{*}{ Rata-Rata } & Accuracy & 83,2 \\
\hline & Precision & 78,8 \\
\hline & Recall & 71,6 \\
\hline & F1-score & 75 \\
\hline & Jumlah Data & 250 \\
\hline
\end{tabular}

Sumber : (Haranto \& Sari, 2019)

Dari Tabel 1, akurasi tertinggi berada di fold ke-4, fold ke-5, fold ke-8 dan fold ke-9 dengan nilai $84 \%$. Pada fold ke-4 dan fold ke-5 memiliki nilai precision $83 \%$, recall $83 \%$, dan $F 1$-score $83 \%$, fold ke-8 memiliki nilai precision $89 \%$, recall $73 \%$, dan 1 -score $80 \%$, fold ke-9 memiliki nilai precision $73 \%$, recall $100 \%$, dan F1-score $85 \%$. Adapun hasil akurasi terendah yang dihasilkan oleh model yaitu $72 \%$ yang berada pada fold ke-3. Pada fold ke-3 memiliki nilai precision $86 \%$, recall $50 \%$, dan $\mathrm{F} 1$ score $63 \%$. Hasil performa dari confusion matrix pada 10 -fold Cross Validation memiliki rata-rata nilai accuracy $79,6 \%$, precision $76,5 \%$, recall $72,8 \%$, dan $74,6 \%$. Data di masukkan ke dalam grafik bar chart, sehingga dapat divisualisasikan seperti pada Gambar 1.

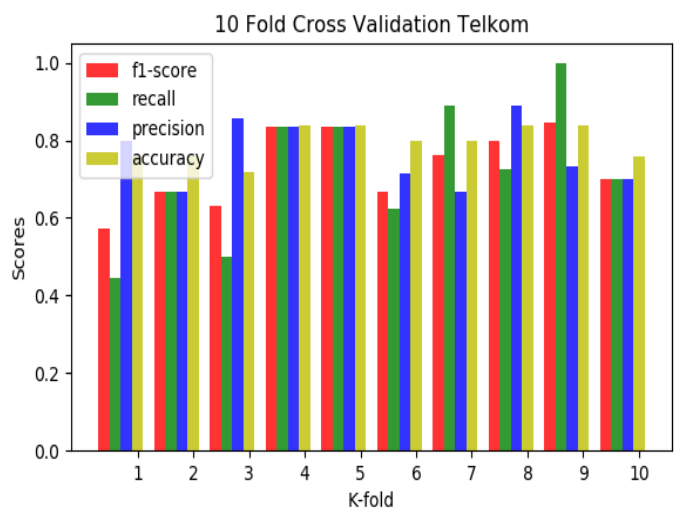

Rata-rata Accuracy :79.6\%, Precission : 76.5\%, Recall : 72.8\%, F1-Score : 74.6\% lika accuracy, precision, recall, $f 1$-sc nilai yang tinggi maka model dapat mengklasifikasi dengan baik

Sumber : (Haranto \& Sari, 2019)

Gambar 1. Hasil 10 Fold Cross Validation Telkom 
Tabel 2. Hasil 10 Fold Cross Validation Biznet

\begin{tabular}{|c|c|c|}
\hline Fold & Parameter & Hasil(\%) \\
\hline \multirow{5}{*}{ Fold 1} & Accuracy & 80 \\
\hline & Precision & 83 \\
\hline & Recall & 56 \\
\hline & F1-score & 67 \\
\hline & Jumlah Data & 25 \\
\hline \multirow{5}{*}{ Fold 2} & Accuracy & 76 \\
\hline & Precision & 62 \\
\hline & Recall & 89 \\
\hline & F1-score & 73 \\
\hline & Jumlah Data & 25 \\
\hline \multirow{5}{*}{ Fold 3} & Accuracy & 84 \\
\hline & Precision & 75 \\
\hline & Recall & 90 \\
\hline & F1-score & 82 \\
\hline & Jumlah Data & 25 \\
\hline \multirow{5}{*}{ Fold 4} & Accuracy & 84 \\
\hline & Precision & 75 \\
\hline & Recall & 75 \\
\hline & F1-score & 75 \\
\hline & Jumlah Data & 25 \\
\hline \multirow{5}{*}{ Fold 5} & Accuracy & 84 \\
\hline & Precision & 100 \\
\hline & Recall & 56 \\
\hline & F1-score & 71 \\
\hline & Jumlah Data & 25 \\
\hline \multirow{5}{*}{ Fold 6} & Accuracy & 80 \\
\hline & Precision & 100 \\
\hline & Recall & 44 \\
\hline & F1-score & 62 \\
\hline & Jumlah Data & 25 \\
\hline \multirow{5}{*}{ Fold 7} & Accuracy & 84 \\
\hline & Precision & 100 \\
\hline & Recall & 50 \\
\hline & F1-score & 67 \\
\hline & Jumlah Data & 25 \\
\hline \multirow{5}{*}{ Fold 8} & Accuracy & 80 \\
\hline & Precision & 80 \\
\hline & Recall & 50 \\
\hline & F1-score & 62 \\
\hline & Jumlah Data & 25 \\
\hline \multirow{5}{*}{ Fold 9} & Accuracy & 100 \\
\hline & Precision & 100 \\
\hline & Recall & 100 \\
\hline & F1-score & 100 \\
\hline & Jumlah Data & 25 \\
\hline \multirow{5}{*}{ Fold 10} & Accuracy & 80 \\
\hline & Precision & 64 \\
\hline & Recall & 100 \\
\hline & F1-score & 78 \\
\hline & Jumlah Data & 25 \\
\hline \multirow{2}{*}{ Rata-Rata } & Accuracy & 83,2 \\
\hline & Precision & 78,8 \\
\hline
\end{tabular}

\begin{tabular}{ccc}
\hline Fold & Parameter & Hasil(\%) \\
\hline & Recall & 71,6 \\
\cline { 2 - 3 } & F1-score & 75 \\
\cline { 2 - 3 } & Jumlah Data & 250 \\
\hline Sumber : (Haranto \& Sari, 2019) &
\end{tabular}

Dari

Tabel 2, akurasi terttinggi berada pada fold ke-9 dengan nilai 96\%. Pada fold ke 9, memiliki nilai precision $100 \%$, recall $100 \%$, dan F1score $100 \%$. Adapun hasil akurasi terendah yang dihasilkan oleh model yaitu $76 \%$ yang berada pada fold ke-2. Pada fold ke-2 memiliki nilai precision $62 \%$, recall $82 \%$, dan F1-score $73 \%$. Confusion matrix memberikan hasil rata-rata performa pada 10-fold Cross Validation memiliki nilai accuracy 83,2\%, precision 78,8\%, recall 71,6\%, dan F1-score $75 \%$. Data di masukkan ke dalam grafik bar chart, sehingga dapat divisualisasikan seperti pada Gambar 2

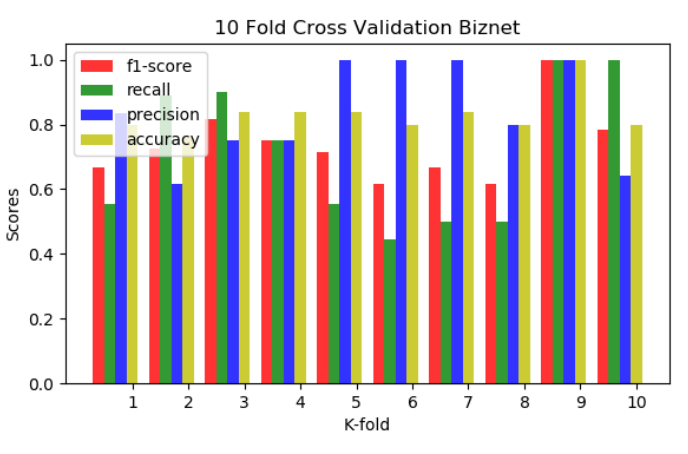

Rata-rata Accuracy :83.2\%, Precission : 78.8\%, Recall : $71.6 \%$, F1-Score : $75.0 \%$ nilai yang tinggi maka model dapat mengklasifikasi dengan baik

Sumber : (Haranto \& Sari, 2019)

Gambar 2. Hasil 10 Fold Cross Validation Biznet

Tabel 3. Confusion Matrix Telkom

\begin{tabular}{cccc}
\hline & $\begin{array}{c}\text { Prediksi } \\
\text { Negatif }\end{array}$ & $\begin{array}{c}\text { Prediksi } \\
\text { Positif }\end{array}$ & Jumlah \\
\hline $\begin{array}{c}\text { Sebenarnya } \\
\text { Negatif }\end{array}$ & 124 & 23 & 147 \\
\hline $\begin{array}{c}\text { Sebenarnya } \\
\text { Positif }\end{array}$ & 28 & 75 & 103 \\
\hline Jumlah & 152 & 98 & 250 \\
\hline
\end{tabular}

Sumber : (Haranto \& Sari, 2019)

Pada

Tabel 3 terdapat 152 data yang diprediksi negatif, dan 98 data yang diprediksi positif. Namun dari 152 data yang diprediksi negatif terdapat kesalahan prediksi sebanyak 28 data, yang seharusnya berada pada kelas positif. Untuk 98 
data yang diprediksi pada kelas positif terdapat 23 data salah prediksi dan seharusnya berada di kelas negatif.

\begin{tabular}{cccc}
\multicolumn{4}{c}{ Tabel 4. Confusion Matrix Biznet } \\
\hline & $\begin{array}{c}\text { Prediksi } \\
\text { Negatif }\end{array}$ & $\begin{array}{c}\text { Prediksi } \\
\text { Positif }\end{array}$ & Jumlah \\
\hline $\begin{array}{c}\text { Sebenarnya } \\
\text { Negatif }\end{array}$ & 145 & 17 & 162 \\
\hline $\begin{array}{c}\text { Sebenarnya } \\
\text { Positif }\end{array}$ & 25 & 63 & 88 \\
\hline Jumlah & 170 & 80 & 250 \\
\hline
\end{tabular}

Sumber : (Haranto \& Sari, 2019)

Pada Tabel 4 terdapat 170 data yang diprediksi negatif, dan 80 data yang diprediksi positif. Namun dari 170 data yang diprediksi negatif terdapat kesalahan prediksi sebanyak 25 data, yang seharusnya berada pada kelas positif. Untuk 80 data yang diprediksi pada kelas positif terdapat 17 data salah prediksi dan seharusnya berada di kelas negatif.

Berikut merupakan hasil sentimen Telkom dan Biznet menggunakan data baru yang diambil dari twitter.

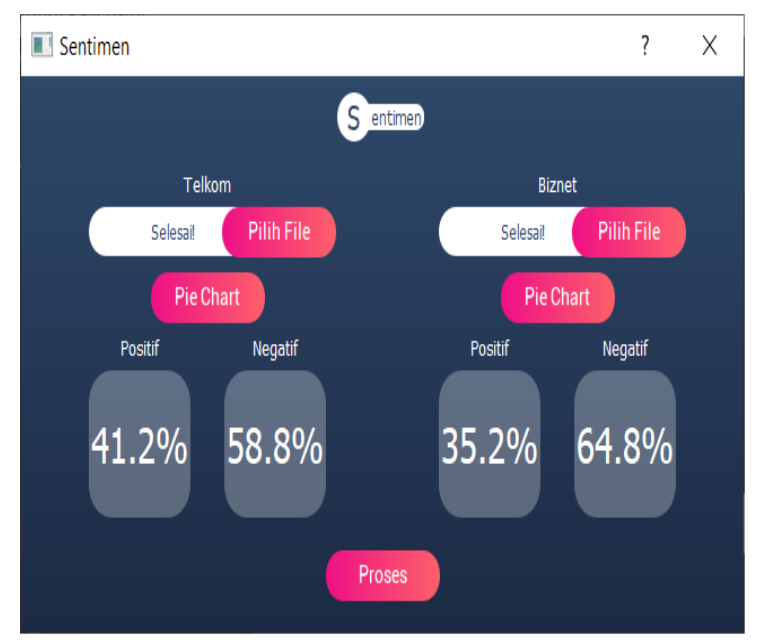

Sumber : (Haranto \& Sari, 2019)

Gambar 3. Hasil Sentimen

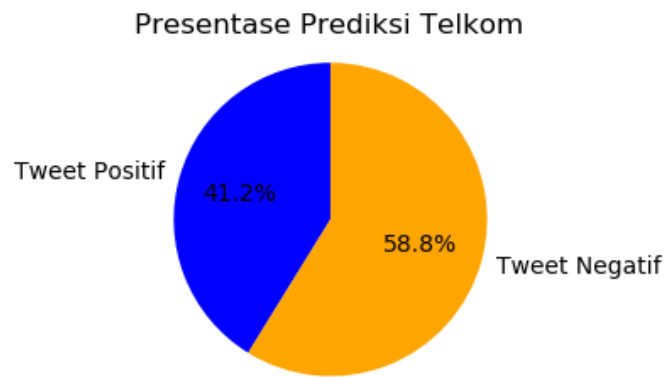

Dari hasil diagram diatas dapat disimpulkan bahwa sentimen masyarakat kepada Telkom adalah negatif Sumber : (Haranto \& Sari, 2019)

Gambar 4. Pie chart prediksi Telkom

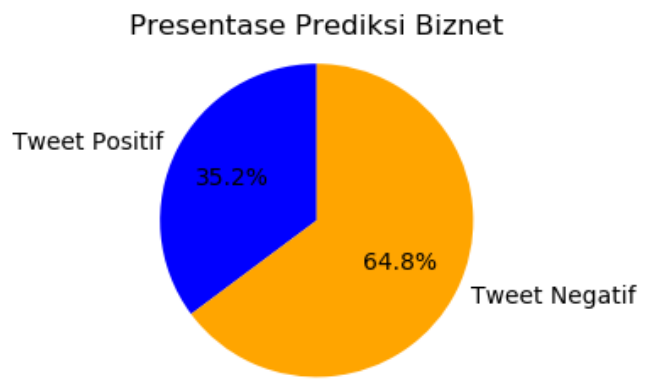

Dari hasil diagram diatas dapat disimpulkan bahwa sentimen masyarakat kepada Biznet adalah negatif Sumber : (Haranto \& Sari, 2019)

Gambar 5. Pie chart prediksi Telkom

Dari diagram pie diatas bisa disimpulkan bahwa bagian yang berwarna biru merupakan presentase positif dan bagian warna oranye adalah persentase negatif. Pada Gambar 4 diagram pie Telkom mendapat nilai positif sebesar $41,2 \%$ dan negatif sebesar $58,8 \%$ yang menandakan sentimen masyarakat kepada Telkom adalah negatif. Sedangkan pada Gambar 5 diagram pie Biznet mendapat nilai positif sebesar $35,2 \%$ dan negatif sebesar $64,6 \%$ yang menandakan sentimen masyarakat kepada Biznet adalah negatif. Untuk melihat mana yang lebih bagus pelayanannya bisa dilihat presentase pada diagram pie kedua perusahaan tersebut. Karena Telkom dan Biznet sama-sama mendapatkan sentimen negatif untuk melihat mana yang lebih bagus kita bisa melihat pada presentase positif, dari hasil di atas Telkom lebih baik dibandingkan Biznet karena memiliki presentase positif lebih banyak dari Telkom yaitu $58,8 \%$, sedangkan Biznet hanya 35,2\%. Untuk presentase positif dan negatif dapat berubah sewaktu-waktu sesuai dengan opini yang diberikan masyarakat kepada Biznet maupun Telkom.

\section{KESIMPULAN}

Penelitian sentimen pengguna twitter terhadap Biznet dan Telkom menggunakan Algoritma Support Vector Machine mendapatkan hasil persentase nilai positif sebesar $41,2 \%$ dan negatif sebesar 58,8\% untuk Telkom dan persentase nilai positif sebesar $35,2 \%$ dan negatif sebesar 64,8\% untuk Biznet. Dari presentase yang didapatkan dapat disimpulkan bahwa Telkom lebih baik pelayanannya dibandingkan Biznet dikarenakan presentase positif Telkom lebih banyak dari Biznet. Untuk presentase positif dan negatif dapat berubah sewaktu-waktu sesuai dengan opini yang diberikan masyarakat kepada Biznet maupun Telkom.

Untuk mengevaluasi model Support Vector Machine yang digunakan, diterapkan metode $\mathrm{K}-10$ Fold Cross Validation dan Confusion Matrix yang 
menghasilkan rata-rata nilai accuracy $79,6 \%$, precision 76,5\%, recall 72,8\%, dan f1-score sebesar $74,6 \%$ hasil dari Telkom, dan nilai accuracy $83,2 \%$, precision $78,8 \%$, recall $71,6 \%$, dan f1-score $75 \%$ hasil dari Biznet. Dengan demikian Algoritma Support Vector Machine cocok dan dapat dipergunakan untuk analisis sentimen terhadap data tweet Telkom dan Biznet.

\section{REFERENSI}

Haranto, F. F., \& Sari, B. W. (2019). Laporan Akhir Penelitian: Implementasi Support Vector Machine Untuk Analisis Sentimen Pengguna Twitter Terhadap Pelayanan Telkom Dan Biznet. Yogyakarta.

Liu, B. (2012). Sentiment Analysis and Opinion Mining. Synthesis Lectures on Human Language Technologies, 5(1), 1-167. https://doi.org/10.2200/S00416ED1V01Y20 1204 HLT016

Monarizqa, N., Nugroho, L. E., \& Hantono, B. S. (2014). PENERAPAN ANALISIS SENTIMEN PADA TWITTER BERBAHASA INDONESIA SEBAGAI PEMBERI RATING. Jurnal Penelitian Teknik Elektro Dan Teknologi Informasi, 1(3). Retrieved from http://ejpteti.jteti.ugm.ac.id/index.php/JPTE TI/article/view/31

Pratomo, Y. (2019, May 16). APJII: Jumlah Pengguna Internet di Indonesia Tembus 171 Juta Jiwa. Tekno.Kompas.Com, p. Internet. Retrieved from https://tekno.kompas.com/read/2019/05/1 6/03260037/apjii-jumlah-penggunainternet-di-indonesia-tembus-171-juta-jiwa

Preety, P., \& Dahiya, S. (2015). SENTIMENT ANALYSIS USING SVM AND NAÏVE BAYES ALGORITHM. International Journal of Computer Science and Mobile Computing, 4(9), 212-219. Retrieved from https://ijcsmc.com/docs/papers/September 2015/V4I9201545.pdf

Santoso, V. I., Virginia, G., \& Lukito, Y. (2017). PENERAPAN SENTIMENT ANALYSIS PADA HASIL EVALUASI DOSEN DENGAN METODE SUPPORT VECTOR MACHINE. Jurnal Transformatika, 14(2), 72 . https://doi.org/10.26623/transformatika.v1 $4 \mathrm{i} 2.439$

Susilo, T. H., \& Rochimah, S. (2013).
PENGKLASIFIKASIAN TOPIK DAN ANALISIS SENTIMEN DALAM MEDIA SOSIAL. In SNASTI 2013 (pp. SC1-SC10). Surabaya: STIKOM Surabaya. Retrieved from https://core.ac.uk/download/pdf/35357695. pdf 